\title{
Nigral Inhibition of GABAergic Neurons in Mouse Superior Colliculus
}

\author{
Katsuyuki Kaneda, ${ }^{1,2}$ Kaoru Isa, ${ }^{1,3}$ Yuchio Yanagawa, ${ }^{4}$ and Tadashi Isa ${ }^{1,2,3}$ \\ ${ }^{1}$ Department of Developmental Physiology, National Institute for Physiological Sciences, Myodaiji, Okazaki 444-8585, Japan, ${ }^{2}$ The Graduate University for \\ Advanced Studies, Hayama, Kanagawa 240-0193, Japan, ${ }^{3}$ Core Research for Evolutional Science and Technology, Japan Science and Technology Agency, \\ Kawaguchi, 332-0012, Japan, and ${ }^{4}$ Department of Genetic and Behavioral Neuroscience, Gunma University Graduate School of Medicine, Maebashi, 371- \\ 8511, Japan
}

The current dominant concept for the control of saccadic eye movements by the basal ganglia is that release from tonic GABAergic inhibition by the substantia nigra pars reticulata ( $\mathrm{SNr}$ ) triggers burst firings of intermediate gray layer (SGI) neurons in the superior colliculus (SC) to allow saccade initiation. This hypothesis is based on the assumption that $\mathrm{SNr}$ cells inhibit excitatory projection neurons in the SGI. Here we show that nigrotectal fibers are connected to local GABAergic neurons in the SGI with a similar frequency to non-GABAergic neurons. This was accomplished by applying neuroanatomical tracing and slice electrophysiological experiments in GAD67-green fluorescent protein (GFP) knock-in mice, in which GABAergic neurons specifically express GFP. We also found that $\mathrm{GABA}_{\mathrm{A}}$, but not $\mathrm{GABA}_{B}$, receptors subserve nigrotectal transmission. The present results revealed a novel aspect on the role of the basal ganglia in the control of saccades, e.g., the SNr not only regulates burst initiation but also modulates the spatiotemporal properties of premotor neurons via connections to local GABAergic neurons in the SC.

Key words: superior colliculus; saccade; basal ganglia; substantia nigra pars reticulata; disinhibition; burst

\section{Introduction}

Burst firing in neurons of the intermediate gray layer (SGI) of the superior colliculus (SC) is a command signal that descends to the brainstem gaze centers, leading to initiation and regulation of rapid orienting behaviors such as saccadic eye movements (Wurtz and Albano, 1980; Sparks, 1986; Hikosaka et al., 2000, 2006; May, 2006). The SGI receives GABAergic inputs arising from the substantia nigra pars reticulata $(\mathrm{SNr})$, one of two output nuclei of the basal ganglia (Jayaraman et al., 1977; Chevalier et al., 1984; May and Hall, 1984; Karabelas and Moschovakis, 1985; Moschovakis and Karabelas, 1985; Williams and Faull, 1988; Harting and Van Lieshout, 1991; Bickford and Hall, 1992; Mana and Chevalier, 2001; Cebrián et al., 2005). The SNr inhibits SGI neurons with high-frequency tonic input (Hikosaka and Wurtz, 1985a,b). Because the SNr also receives inhibitory inputs from the striatum (Str), transient firing of striatal neurons caused by cortical excitation can disinhibit the SGI through the Str-SNrSGI "double inhibitory" pathway. Accumulating evidence indicates that this disinhibition, coupled with excitatory inputs derived from cortical areas such as the frontal and supplementary eye fields, is necessary for generating burst activity in the SGI and thus saccadic eye movements (Wurtz and Hikosaka, 1986). Such

Received July 12, 2008; revised Aug. 20, 2008; accepted Sept. 9, 2008.

This work was supported by Grant-in-Aid for Scientific Research 18021039 and 19700361 (K.K.), 18300102 and 20019010 (Y.Y.), and 18200027 (T.I.) from the Ministry of Education, Culture, Sports, Science, and Technology of Japan. We thank Tomoko Katoh for technical assistance for histology.

Correspondence should be addressed to Katsuyuki Kaneda, Department of Developmental Physiology, National Institute for Physiological Sciences, Myodaiji, 0kazaki 444-8585, Japan. E-mail: kaneda@nips.ac.jp.

D01:10.1523/JNEUROSCI.3263-08.2008

Copyright $\odot 2008$ Society for Neuroscience $\quad$ 0270-6474/08/2811071-08\$15.00/0 a "disinhibition mechanism" has been widely accepted to explain how information from the basal ganglia drives saccades (Wurtz and Hikosaka, 1986; Hikosaka et al., 2006).

Recent studies revealed that there are a variety of GABAergic neurons as well as glutamatergic projection neurons in the SGI (Mize, 1992; May, 2005; Sooksawate et al., 2005; Lee et al., 2007), but their functional roles remain essentially unknown. Most of the GABAergic neurons are intra-SC neurons. Their axons mainly project near their somata within SGI, or they innervate the superficial and/or deep layers (Sooksawate et al., 2005; Lee et al., 2007). The simplest and fundamental role of these neurons may be to inhibit local neuronal activity within the SC. Therefore, if these GABAergic neurons receive nigral inhibition like glutamatergic premotor neurons, disinhibition from the SNr may activate these GABAergic interneurons, which in turn inhibit nearby premotor neurons. However, in contrast to excitatory predorsal bundle cells, it remains unknown whether these GABAergic neurons receive nigral inhibition. To address this issue, we performed tract-tracing studies and whole-cell patchclamp recordings using GAD67-green fluorescent protein (GFP) knock-in mice. In these animals, GABAergic neurons can be identified by their specific expression of GFP fluorescence (Endo et al., 2003; Tamamaki et al., 2003; Kaneda et al., 2008). By using these anatomical and electrophysiological techniques, here we show that the SNr inhibits not only glutamatergic neurons but also GABAergic neurons in the SGI. Our data suggest that the $\mathrm{SNr}$ might have a more complex role in the regulation of SGI activity through connection to the local GABAergic neurons in the SC. 


\section{Materials and Methods}

This study was approved by the Animal Research Committee of the National Institutes of Natural Sciences. All efforts were made to minimize the suffering and number of animals used in this study.

Animals. The procedures for generating and genotyping the two strains of GAD67-GFP knock-in mice have been described previously (Tamamaki et al., 2003). GAD67-GFP knock-in mice retain a loxPflanked neomycin-resistance cassette (PGK-Neo), whereas GAD67-GFP $(\Delta$ neo) knock-in mice lack the PGK-Neo cassette. We used both strains and refer to them both as GAD67-GFP knock-in mice for simplicity. We saw no differences between the two strains. Mice heterozygous for the GAD67-GFP allele were mated with C57BL/6 wild-type mice to obtain heterozygous mice.

Slice preparations. The mice were killed with ether and decapitated when $15-21 \mathrm{~d}$ old. The brains were quickly removed and submerged for 2-3 min in ice-cold modified Ringer's solution containing the following (in mM): 234 sucrose, $2.5 \mathrm{KCl}, 1.25 \mathrm{NaH}_{2} \mathrm{PO}_{4}, 10 \mathrm{MgSO}_{4}, 0.5 \mathrm{CaCl}_{2}, 26$ $\mathrm{NaHCO}_{3}$, and 11 glucose (bubbled with $95 \% \mathrm{O}_{2}-5 \% \mathrm{CO}_{2}$ ), $\mathrm{pH}$ 7.4. Because we observed in preliminary experiments that conventional coronal or parasagittal slices failed to preserve SNr-SC fibers, "modified coronal slices" (300-350 $\mu \mathrm{m}$ thick) of the SC were prepared (see Fig. $2 C$ ). First the brain was cut in an arc parallel to the rostrocaudal SNr-SC fibers (see Fig. $2 \mathrm{Ca}$ ). When the brain was placed on a stage with the cut surface facing downward, gravity pushed the originally curved rostrocaudal $\mathrm{SNr}-\mathrm{SC}$ fibers into a plane (see Fig. $2 \mathrm{Cb}$ ). Thus, the $\mathrm{SNr}-\mathrm{SC}$ fibers become nearly straight (see Fig. $2 C c$ ). Then, the brain was cut with a Microslicer (VT1200S; Leica). We also used parasagittal slices in some experiments (see Fig. $3 H$ ). The slices were incubated at room temperature for $>1 \mathrm{~h}$ before recording in standard Ringer's solution containing the following (in mM): $125 \mathrm{NaCl}, 2.5 \mathrm{KCl}, 2 \mathrm{CaCl}_{2}, 1 \mathrm{MgCl}_{2}, 26 \mathrm{NaHCO}_{3}$, $1.25 \mathrm{NaH}_{2} \mathrm{PO}_{4}$, and 25 glucose (bubbled with $95 \% \mathrm{O}_{2}-5 \% \mathrm{CO}_{2}$ ), $\mathrm{pH}$ 7.4.

Electrophysiological recordings. Slices were mounted in a recording chamber on an upright microscope (BX-51WI; Olympus) and continuously superfused with the oxygenated standard Ringer's solution at a flow rate of $2-2.5 \mathrm{ml} / \mathrm{min}$. Whole-cell patch-clamp recordings were obtained from the neurons in the SGI by visual control of patch pipettes. GFPpositive and -negative neurons were selected using fluorescent optics, and then a whole-cell configuration was obtained using bright-field optics. Patch pipettes were prepared from borosilicate glass capillaries and were filled with either of the following internal solutions. One contained the following (in mM): $130 \mathrm{CsMeSO}_{3}, 5 \mathrm{CsCl}, 2 \mathrm{MgCl}_{2}, 4 \mathrm{Na}_{2} \mathrm{ATP}, 0.3$ $\mathrm{Na}_{3}$ GTP, 1 EGTA, 10 HEPES, 10 tetraethylammonium, 5 QX-314 [ $N$-(2,6-dimethylphenylcarbamoylmethyl)triethylammonium bromide], and 0.1 spermine, $\mathrm{pH}$ adjusted to 7.3 with $\mathrm{CsOH}$. The other contained the following (in mM): $145 \mathrm{~K}$-gluconate, $2 \mathrm{MgCl}_{2}, 4 \mathrm{Na}_{2} \mathrm{ATP}$, $0.3 \mathrm{Na}_{3} \mathrm{GTP}, 0.2$ EGTA, 10 HEPES, and 0.1 spermine, $\mathrm{pH}$ adjusted to 7.3 with $\mathrm{KOH}$. The estimated equilibrium potentials for $\mathrm{Cl}^{-}\left(E_{\mathrm{Cl}^{-}}\right)$of the Cs-based and the K-based intracellular solutions were -51.4 and -92.5 $\mathrm{mV}$, respectively. To stain the recorded neurons, biocytin $(4-5 \mathrm{mg} / \mathrm{ml}$; Sigma) was dissolved in the solutions. The resistance of the electrodes was 4-8 M $\Omega$ in Ringer's solution. The actual membrane potentials were corrected by the liquid junction potential of -10 and $-12 \mathrm{mV}$ for Csbased and K-based intracellular solutions, respectively. All recordings were performed at $33-34^{\circ} \mathrm{C}$. Data were acquired with a Multiclamp $700 \mathrm{~B}$ amplifier and pClamp10 software (Molecular Devices).

To stimulate the $\mathrm{SNr}$, five cathodal concentric bipolar electrodes with a tip distance of $300 \mu \mathrm{m}$ (Inter Medical) were placed on the SNr, and a cathodal square-wave pulse of $200 \mu$ s duration with an intensity of up to $300 \mu \mathrm{A}$ was delivered. The resistance of each electrode was 3.7 $\pm 0.1 \mathrm{M} \Omega$ in the standard Ringer's solution. To isolate $\mathrm{SNr}$ stimulation-evoked inhibitory responses, the AMPA/kainate receptor antagonist 6-cyano-7nitroquinoxaline-2,3-dione (CNQX) (10 $\mu \mathrm{M}$; Tocris Cookson) and the NMDA receptor antagonist DL-2-amino-5-phosphonovaleric acid (APV) (50 $\mu \mathrm{M}$; Sigma) were routinely bath perfused. To examine whether the responses were mediated by $\mathrm{GABA}_{\mathrm{A}}$ or $\mathrm{GABA}_{\mathrm{B}}$ receptors, gabazine (10 $\mu \mathrm{M}$; Sigma) or CGP52432 (3-[[(3,4-dichlorophenyl)methyl]amino]propyl](diethoxymethyl)phosphinic acid) $(3 \mu \mathrm{M}$; Tocris
Cookson), specific antagonists for $\mathrm{GABA}_{\mathrm{A}}$ or $\mathrm{GABA}_{\mathrm{B}}$ receptors, respectively, were bath applied.

Data were analyzed with Clampfit (Molecular Devices). Values are given as the means \pm SD. Statistical significance was examined with a two-tailed Student's paired $t$ test, and the difference was considered significant if $p<0.05$.

Visualization of recorded neurons. After recording, the slices were fixed with $4 \%$ paraformaldehyde in $0.1 \mathrm{~m}$ phosphate buffer $(\mathrm{PB}) \mathrm{pH} 7.4$, for more than $1 \mathrm{~d}$ at $4^{\circ} \mathrm{C}$. After fixation, biocytin-filled neurons were visualized by the avidin-biotin-peroxidase complex (ABC) method (Vectastain; Vector Laboratories), as described previously (Isa et al., 1998). The soma, dendrites, and axons of biocytin-labeled neurons were reconstructed by use of a drawing tube attached to a light microscope (BX-51; Olympus).

Tracer injection into the SNr. In total, 10 mice of either sex, weighing $26-43 \mathrm{~g}$, were used in the tract-tracing study. The mice were anesthetized with a mixture of ketamine (60 mg/kg, i.p.) plus xylazine ( $10 \mathrm{mg} / \mathrm{kg}$, i.p.), and their heads were placed in a stereotaxic apparatus (Narishige). Five mice received unilateral pressure injections of $0.2-0.5 \mu l$ of $5 \%$ biotinylated dextran amine (BDA) (10,000; Invitrogen) dissolved in $0.1 \mathrm{M} \mathrm{PB}$, $\mathrm{pH} 7.4$, into the $\mathrm{SNr}$ by use of glass pipettes with a diameter of $80-120$ $\mu \mathrm{m}$. The other five mice received unilateral iontophoretic injections of $3 \% \mathrm{BDA}$ in $0.1 \mathrm{M} \mathrm{NaCl}$ into the $\mathrm{SNr}$ that were made by passing current pulses ( $4 \mu \mathrm{A} ; 5 \mathrm{~s}$ on $/ 5 \mathrm{~s}$ off) through a $20 \mu \mathrm{m}$ diameter glass micropipette for 10-20 min. With the latter injection method, we obtained less BDA diffusion compared with pressure injection. After a 6-7 d survival period, the animals were deeply anesthetized with sodium pentobarbital $(80 \mathrm{mg} / \mathrm{kg}$, i.p.) and perfused transcardially with 0.05 м PBS, pH 7.4, followed by fixative containing $4 \%$ paraformaldehyde in $0.1 \mathrm{M} \mathrm{PB}, \mathrm{pH}$ 7.2. The brains were cryoprotected in $30 \%$ sucrose in $0.1 \mathrm{M} \mathrm{PB}$, and 50 - to $100-\mu \mathrm{m}$-thick coronal or sagittal sections were cut on a freezing microtome.

Tracer revelation. In four mice, two of which received the iontophoretic injections of BDA and two pressure injections, the BDA was first visualized with immunofluorescence histochemistry and then with the $\mathrm{ABC}$ method. In the other six mice, BDA was visualized by the standard $A B C$ method. For immunofluorescence histochemistry, the sections were first incubated with $\mathrm{ABC}$ ( $\mathrm{ABC}$-Elite; Vector Laboratories), which was diluted at 1:50 with $0.05 \mathrm{M}$ PBS containing $0.3 \%$ Triton X-100 for $2 \mathrm{~h}$ at room temperature, and then further incubated with $5 \mu \mathrm{g} / \mathrm{ml}$ Alexa 594-conjugated streptavidin in $0.05 \mathrm{M}$ PBS for $2 \mathrm{~h}$ at room temperature. The sections were mounted onto gelatin-coated glass slides, air dried, and coverslipped with a mixture of $50 \%(\mathrm{v} / \mathrm{v})$ glycerin and $2.5 \%(\mathrm{w} / \mathrm{v})$ triethylenediamine in 0.05 m PBS. Fluorescence of GFP or Alexa 594 in the sections was observed and photographed with a fluorescence digital microscope (Axioplan2; Zeiss) at low magnification or with a confocal microscope system (Fluoview 300; Olympus) at high magnification.

For standard $\mathrm{ABC}$ staining, the sections were first incubated with $0.6 \%$ $\mathrm{H}_{2} \mathrm{O}_{2}$ in methanol and then further incubated with $\mathrm{ABC}$ (ABC-Elite; Vector Laboratories), which was diluted at 1:50 with $0.05 \mathrm{M}$ PBS containing $0.3 \%$ Triton $\mathrm{X}-100$, for $2.5 \mathrm{~h}$ at room temperature. The sections were then placed into $50 \mathrm{~mm}$ Tris- $\mathrm{HCl}$ buffer containing $0.01 \%(\mathrm{w} / \mathrm{v}) \mathrm{DAB}$ and $0.0003 \% \mathrm{H}_{2} \mathrm{O}_{2}$ for $30 \mathrm{~min}$. They were then mounted onto gelatincoated glass slides, dried, cleared in xylene, and coverslipped. The labeled fibers were observed and photographed with digital microscopes [Axioplan2 (Zeiss) and BIOREVO, BZ-9000 (Keyence)].

\section{Results \\ SNr fibers make synaptic contacts with SGI GABAergic neurons}

We first examined whether the distribution of nigrotectal fibers in the SC of GAD67-GFP knock-in mice are similar to those in other species (May and Hall, 1984; Williams and Faull, 1988; Harting and Van Lieshout, 1991; Bickford and Hall, 1992; Mana and Chevalier, 2001; Cebrián et al., 2005). Figure 1 shows a representative example showing the injection site of the anterograde tracer BDA in the $\mathrm{SNr}$ and distributions of labeled nigral fibers in the ipsilateral SGI (Fig. 1A,B). The injection site covered a large 

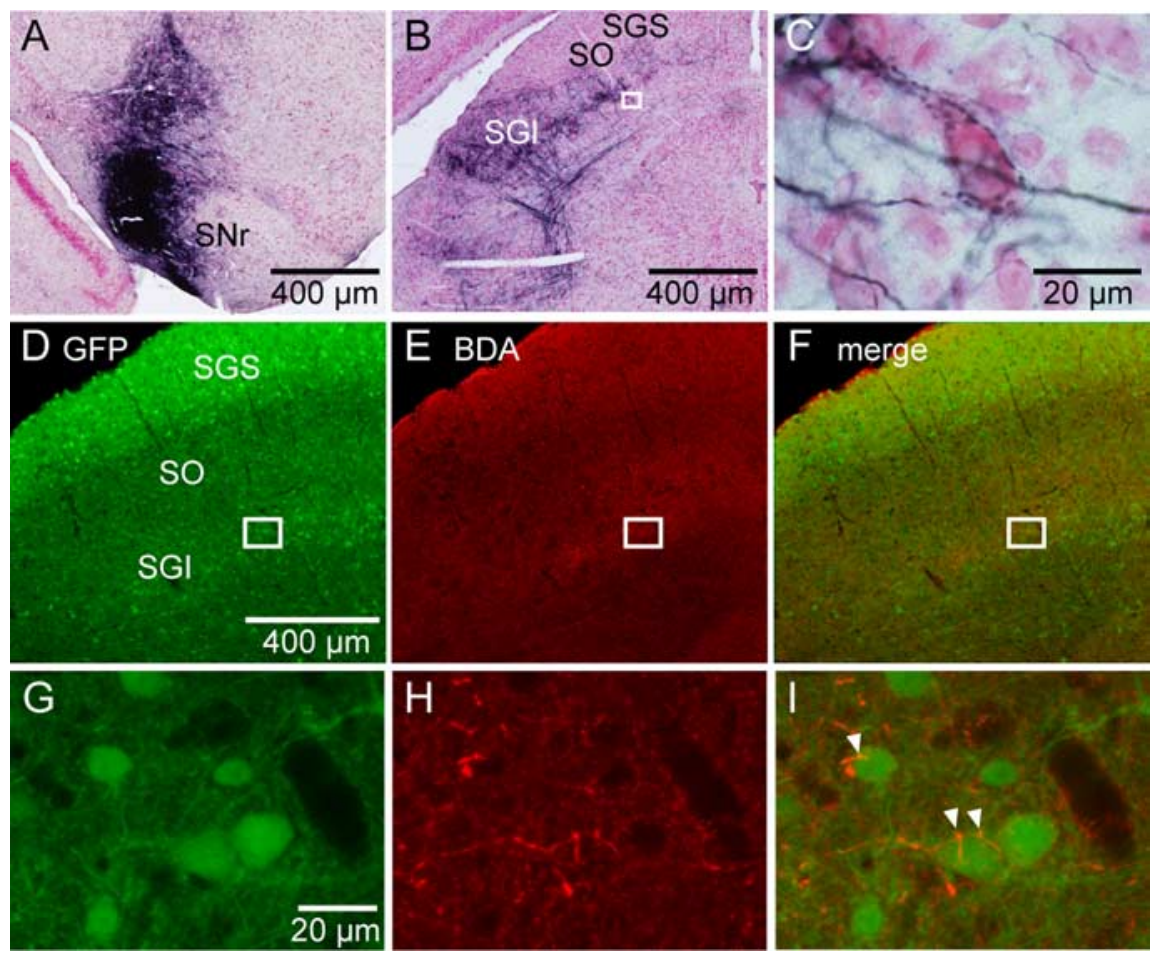

Figure 1. Nigral fibers make synaptic contacts with SGI GABAergic neurons. $\boldsymbol{A}$, A photomicrograph shows an example of the BDA injection site in the SNr in a GAD67-GFP knock-in mouse. $\boldsymbol{B}$, Distribution of labeled SNr fibers in the SC ipsilateral to the BDA-injected SNr. The rectangle area in $\boldsymbol{B}$ is enlarged in $\boldsymbol{C}$., , A high-magnification photomicrograph shows BDA-labeled buttons encircling an SGI neuron. D-I, Double-fluorescence histochemistry for GFP and BDA in a different mouse. Low-magnification photographs $(\boldsymbol{D}-\boldsymbol{F})$ were taken with a fluorescence microscope, whereas high-magnification photographs $(\mathbf{G}-\boldsymbol{I})$ were taken with a confocal microscope. The rectangles in $\mathbf{D}-\boldsymbol{F}$ are enlarged, respectively, in $\mathbf{G}-\boldsymbol{I}$. BDA was visualized with red fluorescence of Alexa 594. BDA-labeled axonal components are in close apposition to GFP-positive neuronal profiles (I, arrowheads). S0, Optic nerve layer.

area of the $\mathrm{SNr}$ with slight diffusion to the dorsal part of the $\mathrm{SNr}$ and cerebral peduncle. Densely labeled nigral axons were mainly observed in the lateral two-thirds of the SGI and deeper layers, but not in the superficial layers, as has been reported in other rodents such as rats and squirrels (May and Hall, 1984; Williams and Faull, 1988; Bickford and Hall, 1992; Mana and Chevalier, 2001). Lightly labeled fibers were also observed in the contralateral SGI in a symmetric location to the ipsilateral side (data not shown). Although densely labeled axons and boutons often masked the shape of SGI neuronal somata, we occasionally observed that labeled synaptic boutons appeared to be in contact with and surround a single neuron soma in the SGI (Fig. 1C). Similar results were obtained from other mice tested, except that slight differences in the densities of labeled nigral fibers were observed because of the different injection volumes of BDA (Fig. $2 A)$. Thus, the basic distribution patterns of nigrotectal fibers in the SGI were similar between mice and other species.

We next investigated the distributions of fluorescently labeled SNr fibers using fluorescent microscopy (Fig. 1D-I). The density of GABAergic neurons was high in the superficial gray layer (SGS), whereas it was relatively sparse in the optic nerve layer $(\mathrm{SO})$ and SGI (Fig. 1D). When we merged the images from the GFP labeling (Fig. $1 G$ ) and the BDA staining (Fig. $1 \mathrm{H}$ ), we found putative synaptic contacts between $\mathrm{SNr}$ fibers and GFP-positive GABAergic neurons in the SGI, in which labeled nigral fibers seemed to attach to the somata of SGI GABAergic neurons at several points (Fig. 1I). Thus, these results indicated that $\mathrm{SNr}$ fibers make synaptic contacts with SGI GABAergic neurons.
Electrophysiological properties of $\mathrm{SNr}$ inhibition to SGI GABAergic neurons To further confirm the anatomical findings described above, we next studied electrophysiologically whether $\mathrm{SNr}$ stimulation could evoke inhibitory synaptic responses in SGI GABAergic neurons. When conventional coronal or parasagittal slices were used, we were unable to record inhibitory responses in either GABAergic or non-GABAergic neurons within SGI after electrical stimulation of the $\mathrm{SNr}$ (data not shown). We postulated that this is because the nigral fibers may be cut during the preparation of the slices. We thus examined the fiber trajectories from the SNr to the SGI in serial sections made after injecting $\mathrm{BDA}$ into the $\mathrm{SNr}$. Coronal sections revealed that $\mathrm{BDA}$ labeled nigral fibers emerged from the dorsal part of the $\mathrm{SNr}$, proceeded in the mediodorsal direction, and then turned to the dorsolateral side of the ipsilateral SC as the fibers progressed caudally. After entering the most lateral part of the SGI, the axons seemed to make synapses with SGI neurons and also extend medially (Fig. $2 A$ ). In parasagittal sections, the $\mathrm{SNr}$ axons first traveled in a dorsocaudal direction, and then in the area around the deep mesencephalic nucleus, the fibers ascended nearly in a straight line toward the dorsorostral direction to enter into the deep layers of the SC. Finally, they terminated mainly in the SGI with patchy terminal distributions (Fig. $2 \mathrm{~B}$ ). Similar fiber trajectories were reported in rats (Cebrián et al., 2005). This winding course of the fibers in both the rostrocaudal and mediolateral directions made it difficult to preserve nigrotectal fibers in conventional coronal or parasagittal slices. Thus, we tried making modified slice preparations so that the nigrotectal fibers could be preserved. As depicted in Figure $2 C$, we first trimmed the brain in an arc parallel to the rostrocaudal nigrotectal fibers (Fig. $2 \mathrm{Ca}$ ). When the trimmed brain was placed on a stage with the cut surface facing downward, gravity pushed the originally curved nigrotectal fibers into a plane (Fig. 2Cb). After the nigrotectal fibers became nearly straight, we sliced the brain and obtained preparations (Fig. 2Cc).

In these slice preparations, we successfully recorded nigral responses in GFP-positive and GFP-negative neurons in the SGI. To stimulate a wide area of the $\mathrm{SNr}$, five serial cathodal electrodes with a tip interval of $300 \mu \mathrm{m}$ were placed as shown in Figure $3 \mathrm{~A}$. Membrane potentials were held at $0-5 \mathrm{mV}$ with a Cs-based intracellular pipette solution to increase the driving force of $\mathrm{Cl}^{-}$ currents. The bath was perfused with the AMPA/kainate receptor antagonist CNQX $(10 \mu \mathrm{M})$ and the NMDA receptor antagonist APV $(50 \mu \mathrm{M})$ to eliminate EPSCs, as well as disynaptic responses. Figure $3 B$ shows examples of responses recorded from a GABAergic neuron. In this neuron, stimulation site 1, the most lateral site, evoked clear outward currents with fixed latencies, whereas the other stimulation sites (2-5) did not. We recorded outward currents in $28.1 \%$ ( 18 of 64 ) and $39.2 \%$ (11 of 28 ) of GABAergic and non-GABAergic neurons, respectively. Latencies of outward currents in GABAergic and non-GABAergic neurons ranged from 

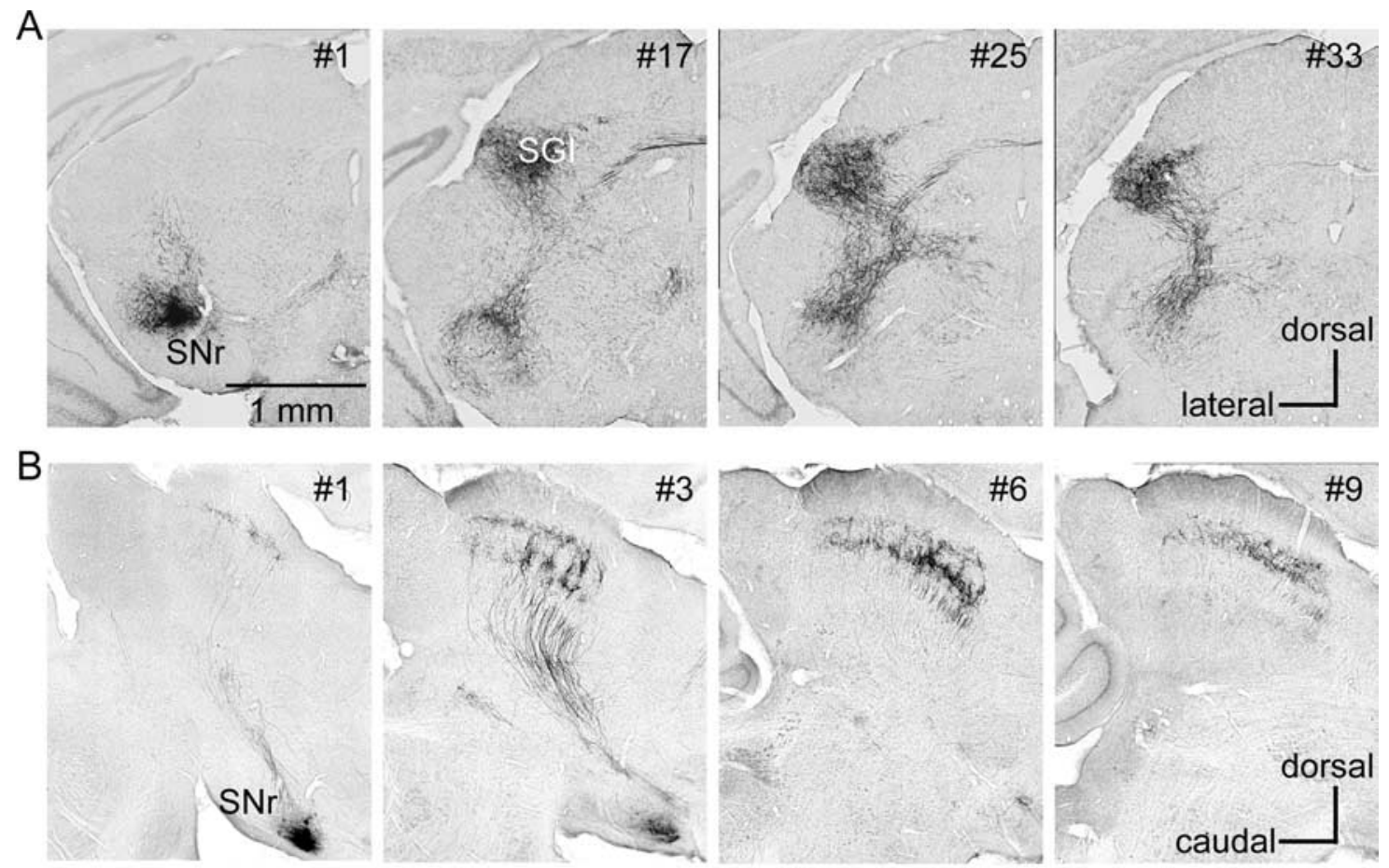

C

a

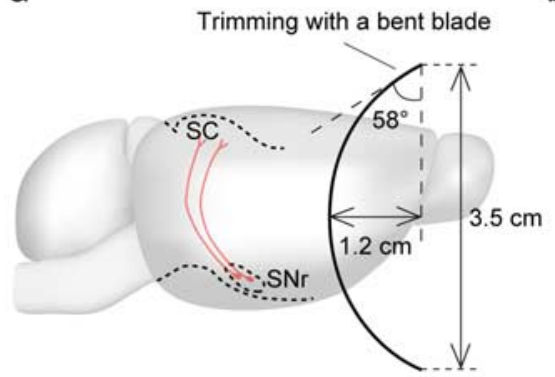

b

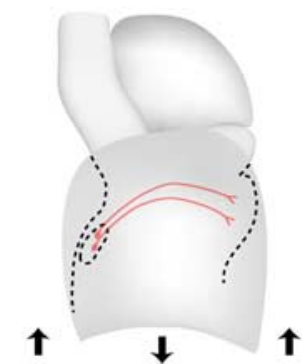

C

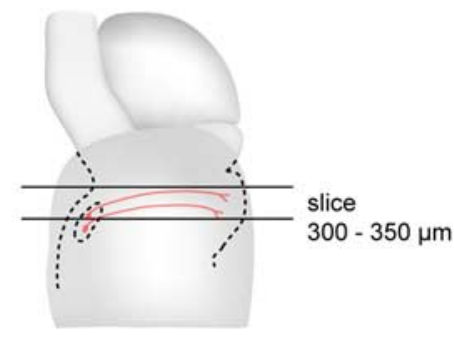

Figure 2. Nigrotectal tracts and the modified slice preparation method. $\boldsymbol{A}$, Four coronal sections ( $50 \mu \mathrm{m}$ thickness) are arranged from rostral on the left to caudal on the right. Section 1 represents the center of the BDA injection into the SNr, which approximately corresponds to bregma $-3.0 \mathrm{~mm}$ section according to the mouse brain atlas by Paxinos and Franklin (2001). $\boldsymbol{B}$, Four sagittal sections (100 $\mu \mathrm{m}$ thickness) are arranged from lateral on the left to medial on the right. Section 1 represents the center of BDA injection into the SNr, which approximately corresponds to lateral 1.65 $\mathrm{mm}$ based on the atlas. $\boldsymbol{C}$, Schematic showing the methods to make modified slice preparations. $\boldsymbol{a}$, First the brain was cut in an arc parallel to the rostrocaudal SNr-SC fibers with a bent blade. $\boldsymbol{b}$, When the brain was placed on a stage with the cut surface facing downward, gravity pushed the originally curved rostrocaudal SNr-SC fibers into a plane. $c$, Thus, the SNr-SC fibers became nearly straight and were considerably preserved in the slices.

2.5 to $14.3 \mathrm{~ms}$ and from 2.2 to $12.9 \mathrm{~ms}$, respectively (Fig. $3 C$ ). The mean latencies were not significantly different between GABAergic $(7.7 \pm 3.6 \mathrm{~ms} ; n=18)$ and non-GABAergic $(5.9 \pm 4.0 \mathrm{~ms} ; n=$ 11) neurons $(p>0.2)$. Amplitudes of outward currents increased with increased stimulus intensity, whereas latencies of the response were independent of stimulus intensity (data not shown). The outward currents were reversed when the membrane potential was hyperpolarized (Fig. $3 D$ ). $I-V$ plots revealed that the reversal potential of the evoked currents was estimated to be $-51.8 \pm 7.2 \mathrm{mV}(n=7)$, which is close to the equilibrium potential of $\mathrm{Cl}^{-}$under the present experimental conditions $(-51.4 \mathrm{mV}$ ) (Fig. 3E,F). Moreover, bath application of the selective $\mathrm{GABA}_{\mathrm{A}}$ receptor antagonist gabazine $(10 \mu \mathrm{M})$ abolished the outward currents $(n=6)$ (Fig. $3 G)$. Thus, these results indicated that the outward currents evoked by $\mathrm{SNr}$ stimulation were monosynaptic $\mathrm{GABA}_{\mathrm{A}}$ receptor-mediated IPSCs.

We also tested whether $\mathrm{GABA}_{\mathrm{B}}$ receptor-mediated responses could be evoked in SGI GABAergic neurons by synaptic activation of $\mathrm{SNr}$ fibers. In this experiment, the membrane potential was held at $-55 \mathrm{mV}$ with a $\mathrm{K}$-based intracellular pipette solution to avoid blocking postsynaptic $\mathrm{GABA}_{\mathrm{B}}$ receptormediated responses. The bath contained CNQX and APV. The stimulating electrodes were placed just ventral to the SC, and repetitive stimulation $(20-50$ pulses at $50 \mathrm{~Hz})$ was delivered to elicit the large amount of GABA release that should be necessary for activating $\mathrm{GABA}_{\mathrm{B}}$ receptors (Isaacson et al., 1993; Mitchell and Silver, 2000; Kaneda and Kita, 2005; Kaneda et al., 2008). Although this stimulation would activate both nigral and other passing GABAergic fibers, including those from the zona incerta and reticular formation (Ficalora and Mize, 1989; Appell and Behan, 1990; Kim et al., 1992; May et al., 1997; Kolmac et al., 1998), the stimulation-evoked IPSCs were not affected by bath application of the selective $\mathrm{GABA}_{\mathrm{B}}$ receptor antagonist CGP52432 (3 $\mu \mathrm{M})$ in six of six neurons tested (Fig. $3 H$ ). Addition of gabazine abolished all the responses, indicating that the outward currents were mediated by $\mathrm{GABA}_{\mathrm{A}}$ receptors. Similar results were obtained in SGI nonGABAergic neurons (data not shown). 
A

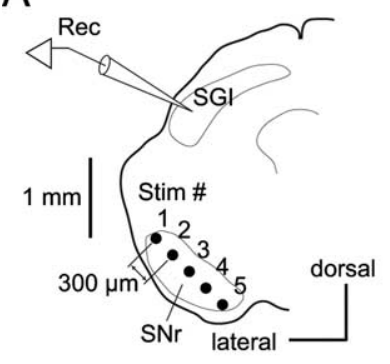

D

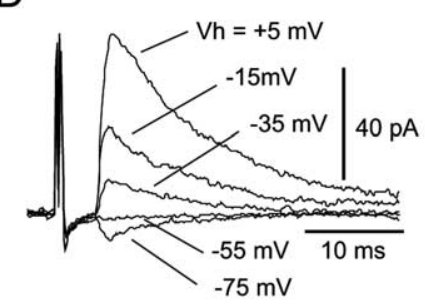

G $\mathrm{Vh}=0 \mathrm{mV}$

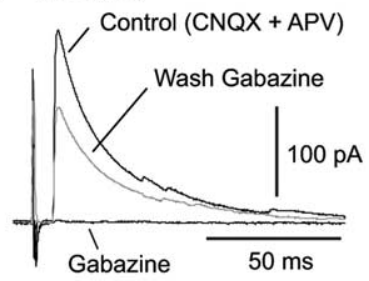

B

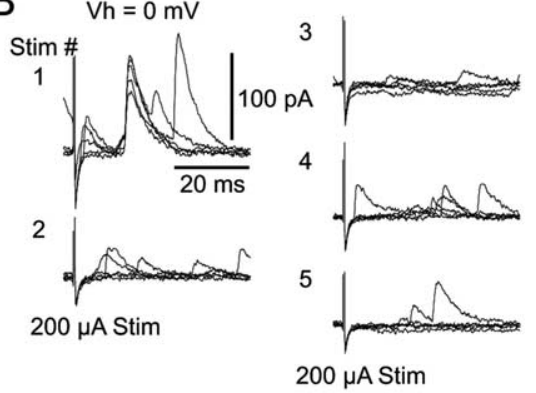

E

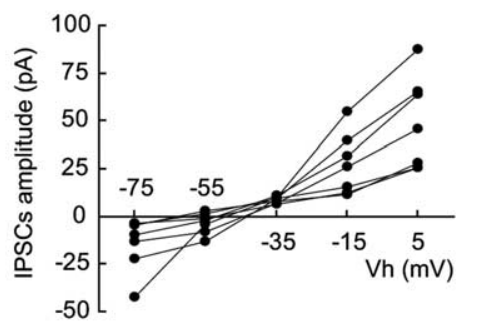

C

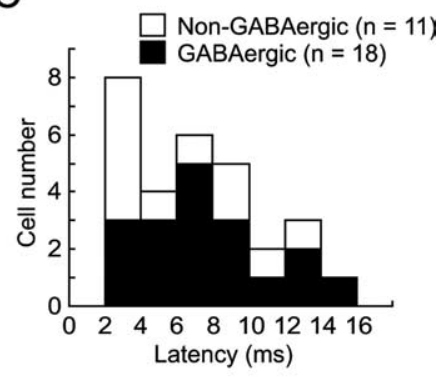

F

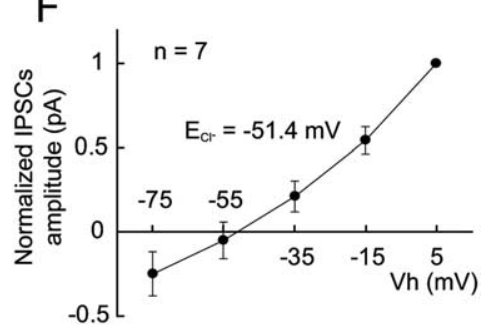

$\mathrm{H}$

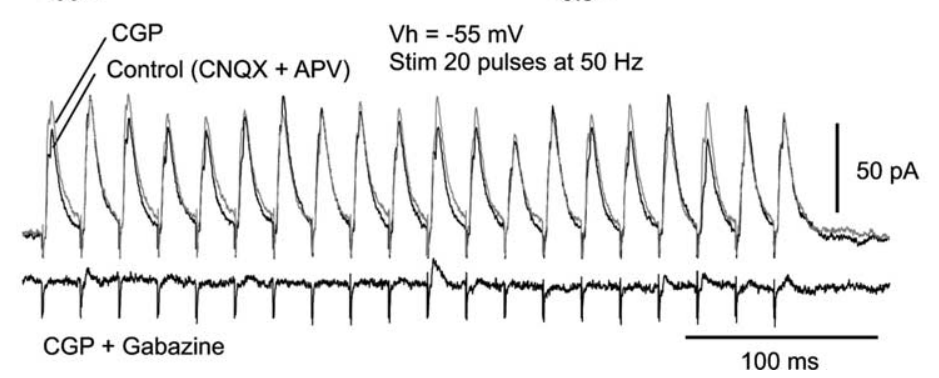

Figure 3. Characteristics of nigral inhibition in SGI GABAergic neurons. $A$, Schematic of configuration for stimulating and recording electrodes. Five cathodal concentric bipolar electrodes with a tip distance of $300 \mu \mathrm{m}$ were placed on the SNr. B, Representative responses evoked by nigral stimulation in SGI GABAergic neurons in the presence of CNQX (10 $\mu \mathrm{M})$ and APV (50 $\mu \mathrm{M})$. Membrane potential was held at $0 \mathrm{mV}$ with a (s-based intracellular pipette solution. In this neuron, only stimulation site 1 evoked IPSCs. Five traces are superimposed in each figure. $C$, Distributions of latency of the IPSCs evoked by SNr stimulation in GABAergic (filled rectangles) and non-GABAergic (open rectangles) SGI neurons. D, Evoked IPSCS were recorded at different holding potentials. E, Plots of IPSCs amplitudes versus holding potentials for seven neurons. $\boldsymbol{F}$, Plots of means of normalized IPSCs amplitudes (amplitude of IPSCs at each holding potential was divided by that at $5 \mathrm{mV}$ ) versus holding potentials reveal that the IPSCs reversed at $-51.8 \pm 7.2 \mathrm{mV}$, which is close to the $E_{\mathrm{Cl}^{-}}(-51.4 \mathrm{mV})$ under the present experimental conditions. G, The SNr stimulation-evoked IPSCs were reversibly blocked by application of the $\mathrm{GABA}_{\mathrm{A}}$ receptor antagonist gabazine $(10 \mu \mathrm{M})$. $\boldsymbol{H}$, Repetitive stimulation (20 pulses at $50 \mathrm{~Hz}$ )-evoked IPSCS were not affected by $(\mathrm{GP} 52432$ ( $3 \mu \mathrm{M})$ application (top traces). Addition of gabazine abolished the responses (bottom trace). In this experiment, membrane potential was held at $-55 \mathrm{mV}$ with K-based electrolyte in the presence of CNQX and APV. Stimulating electrodes were placed just ventral to the SGI.

\section{Location and morphology of SNr-recipient GABAergic neurons}

Finally, we explored the location and morphology of GABAergic neurons in SGI that receive nigral inhibition. As shown in Figure $4 A$, SNr-recipient GABAergic neurons were found in the lateral part of the SGI. The right panel of Figure $4 A$ shows the relationship between the location of SNr-recipient GABAergic neurons and the most effective stimulation site within the $\mathrm{SNr}$, i.e., the site at which IPSCs were evoked with a minimum current intensity. Among 18 SNr-recipient neurons, nine, five, and four neurons responded most effectively to the stimulation site 1,2, and 3, respectively. Stimulation sites 4 and 5 were never the most effective stimulation site under the present experimental condition.

Somatodendritic and axonal morphologies of 7 of $18 \mathrm{SNr}$ recipient GABAergic neurons were reconstructed from biocytin staining as shown in Figure $4 B$. Six of them exhibited multipolar dendritic arborizations (Fig. $4 B a-B c, B e-B g$ ), whereas the remaining neuron seemed to be a horizontal cell (Fig. $4 B d$ ). Based on axonal projections, four of the seven neurons were classified as intra-SGI neurons (Fig. $4 B c-B f$ ), whose axons arborized densely in the vicinity of their soma and dendrites. The axons of the other three neurons projected to deeper (Fig. $4 B a, B b$ ) or to superficial (Fig. $4 B g$ ) layers. However, dense local collaterals were distrib- uted within the SGI even in the three interlaminar neurons. We further investigated a spatial relationship between the biocytinlabeled axon terminals and labeled dendrites. At high magnification $(100 \times$ objective lens), we frequently observed that the labeled terminals are located near the labeled dendrites (Fig. $4 B a, B f)$. This finding indicates that inhibitory influence of the local GABAergic neurons is distributed at least in and around their dendritic fields. Thus, the SNr-recipient SGI GABAergic neurons were mainly SGI interneurons.

\section{Discussion}

By applying tract-tracing techniques to GAD67-GFP knock-in mice, we found that nigral axons make synaptic contacts on GABAergic neurons in the SGI. Although more detailed investigations such as electron microscopic examinations will be necessary for direct evaluation of synaptic contacts between $\mathrm{SNr}$ fibers and SGI GABAergic neurons, our electrophysiological data clearly demonstrated that the $\mathrm{SNr}$ provides monosynaptic inhibition to GABAergic neurons in SGI.

\section{Technical considerations}

The modified slice preparations allowed us to induce IPSCs in $\sim 30-40 \%$ of SGI neurons by electrical stimulation of the SNr. 
These values were comparable with, but slightly smaller than, those reported in in vivo studies showing that $45-60 \%$ of SGI tectoreticular and tectospinal neurons exhibited inhibition in response to $\mathrm{SNr}$ stimulation (Chevalier et al., 1984; Karabelas and Moschovakis, 1985). The low proportion of IPSCs induction is probably not attributable to immature nigral innervation of the SGI, because nigrotectal fibers already exist at birth in cats (Gabriele et al., 2006), and our slice preparations were obtained from postnatal day 15-21 mice. This is most likely a technical limitation. Although we made modified slices, which preserved a larger number of nigrotectal fibers than conventional slices, some nigral axons might have been cut during the slice preparation. Thus, our findings likely underestimate the population of $\mathrm{SNr}$ recipient GABAergic neurons. However, we believe that the slice preparation methods developed here will be useful for and applicable to other brain areas that are connected with curving fibers.

We adjusted the stimulus current intensity so that an effect of stimulation at one site propagated $<300 \mu \mathrm{m}$. This was shown by the observation that a response evoked at one stimulating site was not evoked by adjacent sites. Thus, it is most likely that the evoked IPSCs were the result of $\mathrm{SNr}$ stimulation and not of stimulating other structures or passing fibers. However, we cannot exclude the possibility that the IPSCs were partially derived from inputs of the zona incerta, one of the extrinsic GABAergic sources to the SC (Ficalora and Mize, 1989; Appell and Behan, 1990; Kim et al., 1992; May et al., 1997; Kolmac et al., 1998), because the part of zona incerta that projects to SGI is located adjacent to the rostral SNr (May et al., 1997). Therefore, the contribution, if any, of incertotectal inputs to the evoked IPSCs should be much smaller than that of the nigrotectal inputs.

\section{Properties of nigral inhibition}

We observed very long-latency IPSCs in some neurons compared with previous in vivo studies (Chevalier et al., 1981, 1984; Karabelas and Moschovakis, 1985; Moschovakis et al., 1988). Because we routinely bath applied antagonists for ionotropic glutamate receptors, these long-latency IPSCs were not attributed to disynaptic activation through glutamatergic axons inducing spikes in GABAergic neurons, which in turn innervate the SGI GABAergic neurons. Rather, the difference in latency may be attributable to the age of the animals used. Immature myelination results in slow conduction velocities, and myelination becomes mature at least 4 weeks after birth (Foster et al., 1982; Tsumoto and Suda K, 1983; Song et al., 1995). Thus, the long-latency IPSCs likely result from the immature
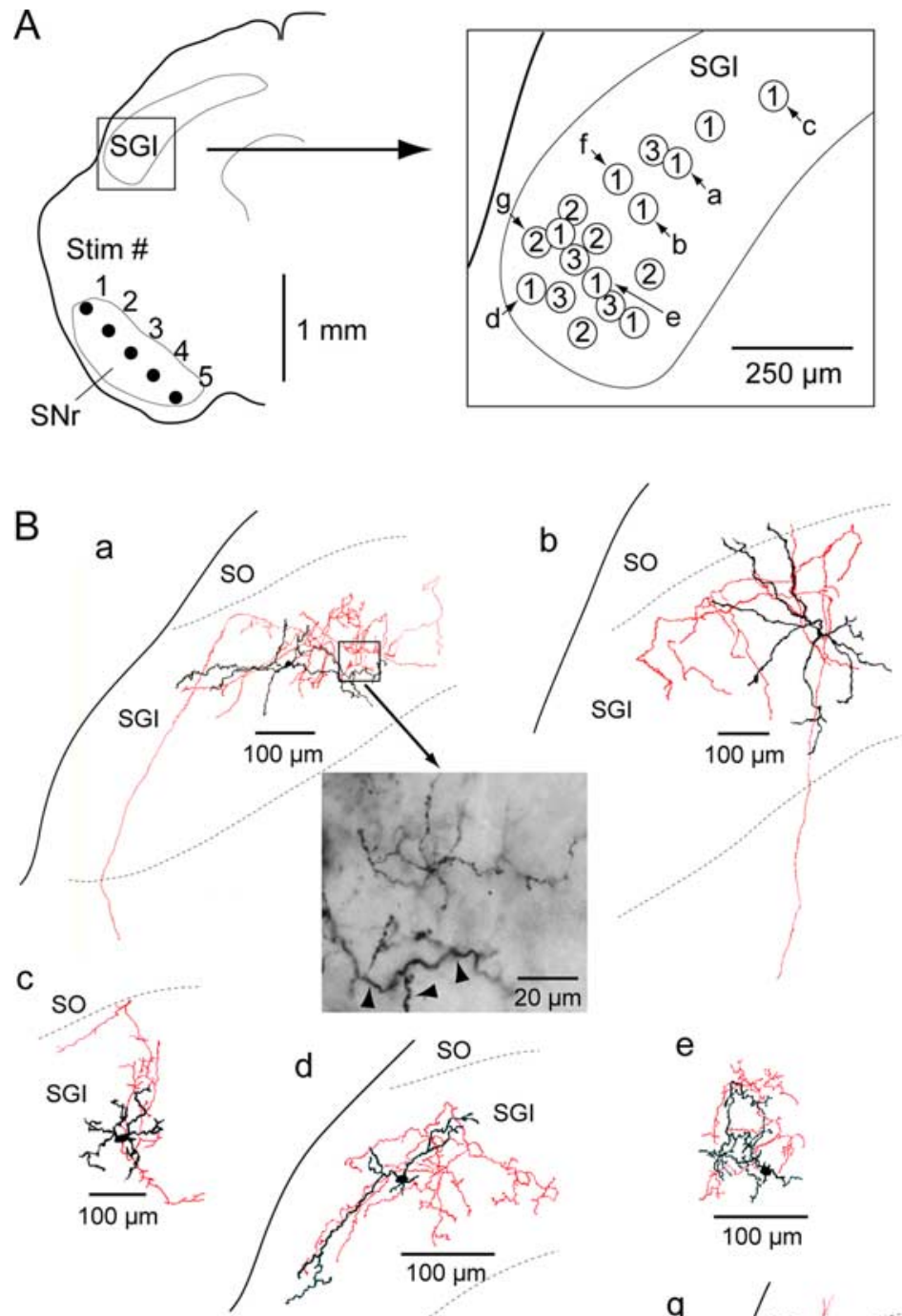

e
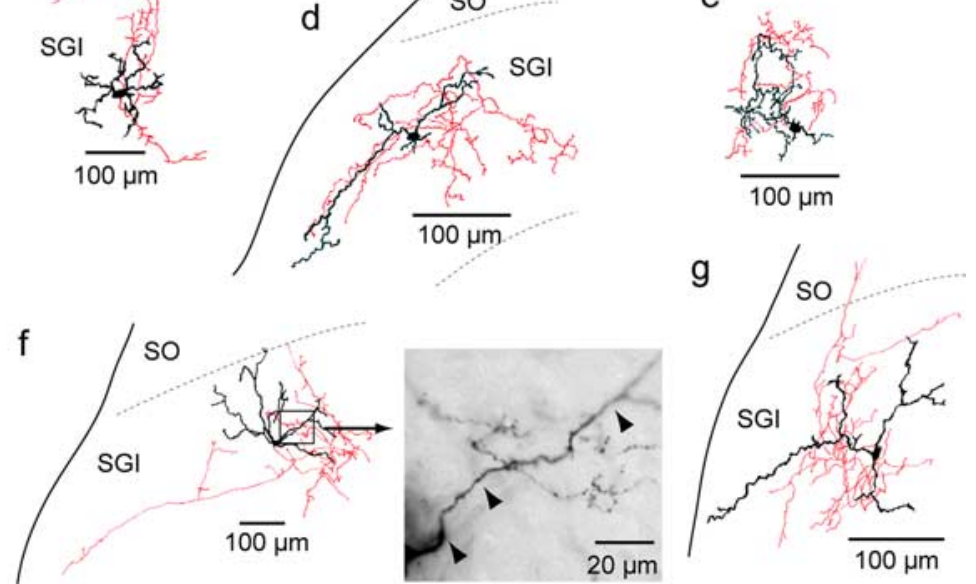

Figure 4. Location and morphology of SNr-recipient GABAergic neurons in the SGI. $A$, Left, Schematic of locations of recorded area in the SGI and stimulating electrode. Rectangle was enlarged in the right. Right, Each circle represents the location of IPSC-positive GABAergic neurons $(n=18)$. Numbers in the circles indicate the stimulation site within the SNr, the stimulation of which evoked IPSCS with a minimum current intensity. Morphologies of 7 of $18 \mathrm{GABAergic}$ neurons $(\boldsymbol{a}-\boldsymbol{g})$ are drawn in $\boldsymbol{B}$. $\boldsymbol{B}$, Morphologies of biocytin-filled GABAergic neurons. Soma and dendrites are drawn in black, and axons are in red. Highmagnification photomicrographs in $\boldsymbol{a}$ and $\boldsymbol{f}$ are obtained from the rectangle areas in the drawings, respectively. The labeled dendrites (arrowheads) and labeled terminals are located in the same focus level. S0, Optic nerve layer.

myelination of nigrotectal axons in the juvenile mice (postnatal day 15-21) used in the present study. Additional studies would be necessary to test this hypothesis.

We found that nigrotectal inhibition was mediated by $\mathrm{GABA}_{\mathrm{A}}$, but not by $\mathrm{GABA}_{\mathrm{B}}$, receptors. This result is consistent with our previous immunohistochemical analysis demonstrating a very low expression level of $G_{A B A} \mathrm{R}_{1 \mathrm{a} / \mathrm{b}}$ receptors in the SGI (Kaneda et al., 2008). Moreover, similar findings demonstrated that nigral stimulation evoked only $\mathrm{GABA}_{\mathrm{A}}$ receptor-mediated inhibition in pedunculopontine tegmental nucleus neurons (Sai- 


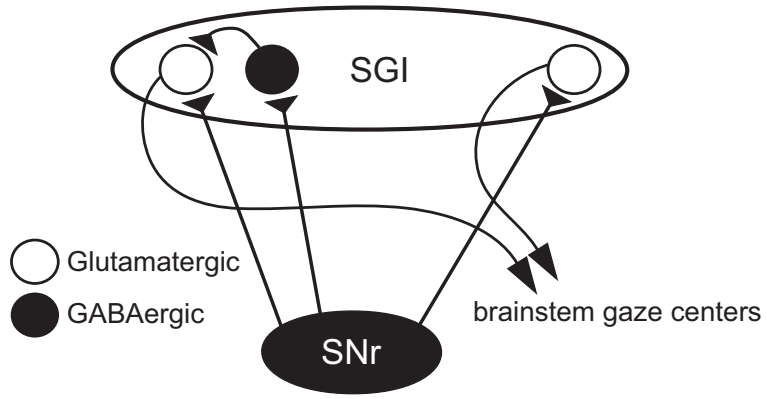

Figure 5. Schematic of inhibitory circuit including the SC and SNr. GABAergic neurons in the SNr innervate both GABAergic and non-GABAergic neurons in the SGI. The SNr-recipient GABAergic neurons may mainly inhibit nearby non-GABAergic premotor neurons, which would project to the brainstem gaze centers.

toh et al., 2003). Conversely, both $\mathrm{GABA}_{\mathrm{A}}$ and $\mathrm{GABA}_{\mathrm{B}}$ receptors are involved in the nigral inhibition of dopaminergic neurons (Saitoh et al., 2004). Thus, the SNr inhibits its recipients in a target-dependent manner by using $\mathrm{GABA}_{\mathrm{A}}$ receptors alone or both $\mathrm{GABA}_{\mathrm{A}}$ and $\mathrm{GABA}_{\mathrm{B}}$ receptors. Because saccades are a very rapid behavior, it is reasonable to speculate that such a system uses fast synaptic inhibition through $\mathrm{GABA}_{\mathrm{A}}$ receptors rather than slow inhibition via $\mathrm{GABA}_{\mathrm{B}}$ receptors, enabling SGI neurons to be quickly disinhibited immediately after a pause in the firing of nigral neurons.

\section{Anatomical properties of GABAergic neurons}

Previous studies have shown that there exist a variety of GABAergic neurons in the SGI, including interlaminar, intralaminar, commissural, and tectofugal projection neurons (Sooksawate et al., 2005; Lee et al., 2007). These various GABAergic neuronal types may have different functional roles in the SC circuitry. For example, a population of interlaminar GABAergic neurons that project to the SGS may inhibit SGS neuronal activity, suppressing unwanted inputs during the course of a saccade (Lee et al., 2007).

Conversely, most of the SNr-recipient GABAergic neurons found in the present study were intralaminar neurons, although the axon trajectories followed in the slices were limited to within $300-350 \mu \mathrm{m}$. We frequently encountered these GABAergic neurons in the lateral part of the SGI. Bickford and Hall (1992) reported that retrogradely labeled predorsal bundle cells are also mainly located in the lateral extreme or flank of the SGI in rats, with which nigrotectal terminals overlapped extensively. Together, these data imply that SNr-recipient GABAergic neurons most likely inhibit SNr-recipient predorsal bundle cells located in the vicinity of the GABAergic neurons (Fig. 5). This is consistent with a recent study showing that inhibitory interactions within the SGI are locally restricted (Lee and Hall, 2006).

\section{Functional implications}

Several lines of evidence suggested that the SNr plays critical roles in the control of saccadic eye movements (Handel and Glimcher, 1999; Basso and Wurtz, 2002; Bayer et al., 2004; Basso et al., 2005; Basso and Liu, 2007). One of the interesting observations reported by Basso and Liu (2007) is that electrical stimulation of the SNr both reduced and prolonged saccade latency. As the authors suggested, these bidirectional phenomena might be accounted for by the SNr-SGI GABAergic neuron projection. If $\mathrm{SNr}$ neurons projecting to SGI premotor neurons were stimulated, the resultant inhibition may delay saccade initiation, whereas if $\mathrm{SNr}$ neurons projecting to SGI GABAergic neurons were stimulated, inhibition of GABAergic neurons may lead to disinhibition of
non-GABAergic neurons, resulting in rapid saccade onset. Thus, the precise regulation of eye movements exerted by $\mathrm{SNr}$ inputs may be an outcome attributed to the interactions among $\mathrm{SNr}$ axons and inhibitory and excitatory SGI neurons.

It is still unclear whether individual nigrotectal axons branch to innervate both local GABAergic neurons and predorsal bundle cells. If this is the case, then, the next question would be whether the targeted predorsal bundle cells receive inhibition from the targeted GABAergic neurons. Our morphological examination revealed that biocytin-labeled axon terminals of local GABAergic neurons are located near the labeled dendrites of those neurons. This finding suggests that the local GABAergic neurons inhibit nearby predorsal bundle cells that might receive the same nigral inputs. Future studies to address these issues will be necessary for understanding whether the GABAergic neurons are modulating the firing of the cells being released to fire for a saccade or whether they are instead being released so that they can further inhibit cells that are not being released from gating, to make the region of bursting within the motor map more discrete.

Burst firing in SGI neurons is probably evoked by release from nigral inhibition and concurrent cortical excitation (Isa et al., 1998; Saito and Isa, 2003; Hikosaka et al., 2006). Conversely, the burst firing might be terminated by cooperation between "reinhibition" from the SNr and the end of excitatory inputs from the cortex, as well as intrinsic excitatory interactions within the SGI (Saito and Isa, 2003). However, because the disinhibition likely occurs in local GABAergic neurons and projection neurons simultaneously, such local GABAergic neurons might inhibit bursting activity in SGI projection neurons more readily than the nigral inputs. Thus, the SNr-recipient GABAergic neurons may provide extremely rapid inhibition of SGI neurons, contributing to the transient nature of premotor bursts in SGI neurons.

Inputs from GABAergic interneurons have a significant impact on spike timing precision in cortical and hippocampal pyramidal cells (Cobb et al., 1995; Fricker and Miles, 2000; Pouille and Scanziani, 2001). When nigral inhibition was released, inhibitory inputs from temporarily active SGI GABAergic neurons could become a major component of the influences over SGI projection neurons. Thus, these active local GABAergic neurons could act as modulators of spike timing in SGI premotor neurons. Alternatively, given that background synaptic noise has been suggested to play a significant role in spike timing and reliability (Mainen and Sejnowski, 1995; Nowak et al., 1997), suppression by these GABAergic neurons, in collaboration with excitation by extrinsic and intrinsic excitatory neurons, might contribute to shaping the temporal properties of spiking activity of nearby premotor neurons in the SGI.

In summary, our present study sheds new light on the role of the basal ganglia in saccade control, which is closely linked to the importance of SGI GABAergic neurons. These neurons may modulate the spatiotemporal profiles of activity at particular sites within the SGI using their spatiotemporally tuned activity.

\section{References}

Appell PP, Behan M (1990) Sources of subcortical GABAergic projections to the superior colliculus in the cat. J Comp Neurol 302:143-158.

Basso MA, Liu P (2007) Context-dependent effects of substantia nigra stimulation on eye movements. J Neurophysiol 97:4129-4142.

Basso MA, Wurtz RH (2002) Neuronal activity in substantia nigra pars reticulata during target selection. J Neurosci 22:1883-1894.

Basso MA, Pokorny JJ, Liu P (2005) Activity of substantia nigra pars reticulata neurons during smooth pursuit eye movements in monkeys. Eur J Neurosci 22:448-464.

Bayer HM, Handel A, Glimcher PW (2004) Eye position and memory sac- 
cade related responses in substantia nigra pars reticulata. Exp Brain Res 154:428-441.

Bickford ME, Hall WC (1992) The nigral projection to predorsal bundle cells in the superior colliculus of the rat. J Comp Neurol 319:11-33.

Cebrián C, Parent A, Prensa L (2005) Patterns of axonal branching of neurons of the substantiga nigra pars reticulata and pars lateralis in the rat. J Comp Neurol 492:349-369.

Chevalier G, Deniau JM, Thierry AM, Feger J (1981) The nigro-tectal pathway. An electrophysiological reinvestigation in the rat. Brain Res 213:253-263.

Chevalier G, Vacher S, Deniau JM (1984) Inhibitory nigral influence on tectospinal neurons, a possible implication of basal ganglia in orienting behavior. Exp Brain Res 53:320-326.

Cobb SR, Buhl EH, Halasy K, Paulsen O, Somogyi P (1995) Synchronization of neuronal activity in hippocampus by individual GABAergic interneurons. Nature 378:75-78.

Endo T, Yanagawa Y, Obata K, Isa T (2003) Characteristics of GABAergic neurons in the superficial superior colliculus in mice. Neurosci Lett 346:81-84.

Ficalora AS, Mize RR (1989) The neurons of the substantia nigra and zona incerta which project to the cat superior colliculus are GABA immunoreactive: a double-label study using GABA immunocytochemistry and lectin retrograde transport. Neuroscience 29:567-581.

Foster RE, Connors BW, Waxman SG (1982) Rat optic nerve: electrophysiological, pharmacological and anatomical studies during development. Brain Res 255:371-386.

Fricker D, Miles R (2000) EPSP amplification and the precision of spike timing in hippocampal neurons. Neuron 28:559-569.

Gabriele ML, Smoot JE, Jiang H, Stein BE, McHaffie JG (2006) Early establishment of adult-like nigrotectal architecture in the neonatal cat: a double-labeling study using carbocyanine dyes. Neuroscience 137:1309-1319.

Handel A, Glimcher PW (1999) Quantitative analysis of substantia nigra pars reticulata activity during a visually guided saccade task. J Neurophysiol 82:3458-3475.

Harting JK, Van Lieshout DP (1991) Spatial relationships of axons arising from the substantia nigra, spinal trigeminal nucleus, and pedunculopontine tegmental nucleus within the intermediate gray of the cat superior colliculus. J Comp Neurol 305:543-558.

Hikosaka O, Wurtz RH (1985a) Modification of saccadic eye movements by GABA-related substances. I. Effect of muscimol and bicuculline in monkey superior colliculus. J Neurophysiol 53:266-291.

Hikosaka O, Wurtz RH (1985b) Modification of saccadic eye movements by GABA-related substances. II. Effects of muscimol in monkey substantia nigra pars reticulata. J Neurophysiol 53:292-308.

Hikosaka O, Takikawa Y, Kawagoe R (2000) Role of the basal ganglia in the control of purposive saccadic eye movements. Physiol Rev 80:953-978.

Hikosaka O, Nakamura K, Nakahara H (2006) Basal ganglia orient eyes to reward. J Neurophysiol 95:567-584.

Isa T, Endo T, Saito Y (1998) The visuo-motor pathway in the local circuit of the rat superior colliculus. J Neurosci 18:8496-8504.

Isaacson JS, Solís JM, Nicoll RA (1993) Local and diffuse synaptic actions of GABA in the hippocampus. Neuron 10:165-175.

Jayaraman A, Batton RR 3rd, Carpenter MB (1977) Nigrotectal projections in the monkey: an autoradiographic study. Brain Res 135:147-152.

Kaneda K, Kita H (2005) Synaptically released GABA activates both preand postsynaptic $\mathrm{GABA}_{\mathrm{B}}$ receptors in the rat globus pallidus. J Neurophysiol 94:1104-1114.

Kaneda K, Phongphanphanee P, Katoh T, Isa K, Yanagawa Y, Obata K, Isa T (2008) Regulation of burst activity through presynaptic and postsynaptic $\mathrm{GABA}_{\mathrm{B}}$ receptors in mouse superior colliculus. J Neurosci 28:816-827.

Karabelas AB, Moschovakis AK (1985) Nigral inhibitory termination on efferent neurons of the superior colliculus: an intracellular horseradish peroxidase study in the cat. J Comp Neurol 239:309-329.

Kim U, Gregory E, Hall WC (1992) Pathway from the zona incerta to the superior colliculus in the rat. J Comp Neurol 321:555-575.

Kolmac CI, Power BD, Mitrofanis J (1998) Patterns of connections between zona incerta and brainstem in rats. J Comp Neurol 396:544-555.

Lee P, Hall WC (2006) An in vitro study of horizontal connections in the intermediate layer of the superior colliculus. J Neurosci 26:4763-4768.
Lee PH, Sooksawate T, Yanagawa Y, Isa K, Isa T, Hall WC (2007) Identity of a pathway for saccadic suppression. Proc Natl Acad Sci U S A 104:6824-6827.

Mainen ZF, Sejnowski TJ (1995) Reliability of spike timing in neocortical neurons. Science 268:1503-1506.

Mana S, Chevalier G (2001) The fine organization of nigro-collicular channels with additional observations of their relationships with acetylcholinesterase in the rat. Neuroscience 106:357-374.

May PJ (2006) The mammalian superior colliculus: laminar structure and connections. Prog Brain Res 151:321-378.

May PJ, Hall WC (1984) Relationships between the nigrotectal pathway and the cells of origin of the predorsal bundle. J Comp Neurol 226:357-376.

May PJ, Sun W, Hall WC (1997) Reciprocal connections between the zona incerta and the pretectum and superior colliculus of the cat. Neuroscience 77:1091-1114.

Mitchell SJ, Silver RA (2000) GABA spillover from single inhibitory axons suppresses low-frequency excitatory transmission at the cerebellar glomerulus. J Neurosci 20:8651-8658.

Mize RR (1992) The organization of GABAergic neurons in the mammalian superior colliculus. Prog Brain Res 90:219-248.

Moschovakis AK, Karabelas AB (1985) Observations on the somatodendritic morphology and axonal trajectory of intracellularly HRP-labeled efferent neurons located in the deeper layers of the superior colliculus of the cat. J Comp Neurol 239:276-308.

Moschovakis AK, Karabelas AB, Highstein SM (1988) Structure-function relationships in the primate superior colliculus. I. Morphological classification of efferent neurons. J Neurophysiol 60:232-262.

Nowak LG, Sanchez-Vives MV, McCormick DA (1997) Influence of low and high frequency inputs on spike timing in visual cortical neurons. Cereb Cortex 7:487-501.

Paxinos G, Franklin KBJ (2001) The mouse brain in stereotaxic coordinates. San Diego: Academic.

Pouille F, Scanziani M (2001) Enforcement of temporal fidelity in pyramidal cells by somatic feed-forward inhibition. Science 293:1159-1163.

Saito Y, Isa T (2003) Local excitatory network and NMDA receptor activation generate a synchronous and bursting command from the superior colliculus. J Neurosci 23:5854-5864.

Saitoh K, Hattori S, Song WJ, Isa T, Takakusaki K (2003) Nigral GABAergic inhibition upon cholinergic neurons in the rat pedunculopontine tegmental nucleus. Eur J Neurosci 18:879-886.

Saitoh K, Isa T, Takakusaki K (2004) Nigral GABAergic inhibition upon mesencephalic dopaminergic cell groups in rats. Eur J Neurosci 19:2399-2409.

Song WJ, Okawa K, Kanda M, Murakami F (1995) Perinatal development of action potential propagation in cat rubrospinal axons. J Physiol 488:419-426.

Sooksawate T, Isa K, Obata K, Yanagwa Y, Isa T (2005) Electrophysiological and morphological properties of GABAergic neurons in the intermediate gray layer of superior colliculus in GAD67-GFP knock-in mice. Soc Neurosci Abstr 35:167.8.

Sparks DL (1986) Translation of sensory signals into commands for control of saccadic eye movements: role of primate superior colliculus. Physiol Rev 66:118-171.

Tamamaki N, Yanagawa Y, Tomioka R, Miyazaki J, Obata K, Kaneko T (2003) Green fluorescent protein expression and colocalization with calretinin, parvalbumin, and somatostatin in the GAD67-GFP knock-in mouse. J Comp Neurol 467:60-79.

Tsumoto T, Suda K (1983) Postnatal development of corticotectal neurons in the kitten striate cortex: an electrophysiological study. Brain Res 313:29-38.

Williams MN, Faull RL (1988) The nigrotectal projection and tectospinal neurons in the rat. A light and electron microscopic study demonstrating a monosynaptic nigral input to identified tectospinal neurons. Neuroscience 25:533-562.

Wurtz RH, Albano JE (1980) Visual-motor function of the primate superior colliculus. Annu Rev Neurosci 3:189-226.

Wurtz RH, Hikosaka O (1986) Role of the basal ganglia in the initiation of saccadic eye movements. Prog Brain Res 64:175-190. 